\title{
Railway bridge asset management using a Petri-Net modelling approach
}

\author{
P. C. Yianni \& D. Rama \& L. C. Neves \& J. D. Andrews \\ Centre for Risk and Reliability Engineering, University of Nottingham, Nottingham, UK
}

\begin{abstract}
Infrastructure assets can be difficult to manage due to the array of defects, the variety of environmental situations and the different operational scenarios. A number of studies have tried to model bridge asset management. The main focus of these models has been on the deterioration profiling as capturing this can be complex. The model presented tries to model railway bridge detrioration as well as the inspection and intervention processes to give a more rounded overview of railway bridge asset management. A Petri-Net (PN) modelling approach is used accompanied by historical data, used to calibrate the deterioration of the model. Industry policies are used to govern the inspection and intervention procedures. Various aspects of the model have been adjusted or enhanced by industry experts. The model is simulated to provide essential outputs for railway bridge portfolio mangers.
\end{abstract}

\section{INTRODUCTION}

The railway network is critical to the UK economic output. Both commuters and freight rely heavily on the network. The pressure on the railway network to increase its throughput is high. A vast increase in throughput is predicted with the introduction of moving block signalling; this means that trains can run closer together with tighter schedules. Coupled with increasingly more powerful tractive units, the stresses on the network will be tremendous. Therefore, more effective management of the assets is required to be able to cope with the increased demand. The focus of this study is civil structures; in particular railway bridges.

One of the first challenges for a railway operator is to understand how their portfolio of bridges behaves. Construction of a modern bridge is governed by legislation (Eurocode 1996) which recommends a 100 year design life. However there is little guidance on how to manage the structure over those 100 years. This is made more complex by the fact that bridges degrade by different means, are subjected to different conditions both operationally and environmentally and finally, have been managed in different ways over their lifetime. Therefore management of a portfolio of bridges is a complex and demanding challenge.

\section{STOCHASTIC MODELS}

\subsection{Markov Based Models}

Bridge asset management has had a number of studies involving stochastic techniques, most notably, Markov based models. Frangopol, Kallen, \& van Noortwijk 2004 state that structural deterioration is inherently stochastic by nature and therefore a stochastic modelling approach is most appropriate. Similarly, Morcous, Lounis, \& Cho 2010 state that structural deterioration is a complex process which involves much uncertainty in the "micro-response" of the structure. Therefore a stochastic model offers a more robust approach that will more closely mimic the real-world process.

One of the first Markov based models for bridge asset management was developed by Jiang \& Sinha 1989. The study took place in Indiana, USA and used 5,700 bridges. The paper uses 50 sample bridges of different types on which analysis was carried out. The authors explain the methodology for calculating the transitional probabilities for the Transition Probability Matrix (TPM). In accordance with the Federal Highway Administration (FHWA), 10 condition states are used ranging from 0 , a poor condition to 9 , a new condition. The authors discovered that the rate of deterioration was dependant on the bridge age. With this in mind, the authors suggest that a Markov approach would be most suitable in capturing this behaviour. They go on to develop a Markov based model. A similar approach was used by the Association of State Highway and Transportation Offi- 
cials (AASHTO) to create Pontis, one of the most widespread Bridge Management Systems (BMSs). Pontis has been used in over 45 US states to manage in excess of 500,000 bridges (Sobanjo \& Thompson 2011).

Another study which used a Markov approach was Scherer \& Glagola 1994. The study took place in Virginia, USA with 13,000 bridges. This study used 7 condition states with 1 representing a potentially hazardous state, to 7 representing an "as new" state. The authors state that a Markov chain approach would create too many states to model with contemporary computing facilities. The authors begin an exercise to group bridges by key characteristics based on the: bridge age, number of spans, bridge type, traffic loading and climate. In total the authors manage to collate the 13,000 bridges into 216 characteristic groups. The study demonstrated an approach to overcoming the state expansion problem with Markov based models. However, the authors do recognise that in some instances, bridges that were initially in one group may qualify for another group at a later date if there are operational or network changes.

Markov models are used as the back-end of many of the BMSs used globally. They have had unparalleled adoption in the field of bridge asset management. Their suitability extends to many other fields including highways, water distribution and sewerage works (Morcous 2006). However, as with any technique, there are limitations. Some of the limitations are Markovian limitations and some are limitations to using the Markov approach for bridge asset management. Firstly, Markov based models are usually calibrated with data, however there are often borderline candidates that require expert judgement to categorise properly. Frangopol, Kallen, \& van Noortwijk 2004 makes the case that a more detailed measurement criteria, possibly continuous in nature, would be superior. Secondly, on the subject of calibration, calculating the TPMs can be difficult and often requires adjustment using expert judgement (Frangopol, Kallen, \& van Noortwijk 2004). Thirdly, many studies disregard inspection data when the condition has improved as it is difficult to be certain which elements were repaired (Robelin \& Madanat 2007, Morcous, Rivard, \& Hanna 2002). Lastly, a Markovian limitation is the state expansion problem. This is where the number of model states follows $S^{n}$ where $S$ is the number of condition states and $n$ is the number of bridges in the study (British Standards Institution 2012). Scherer \& Glagola 1994 tried to overcome this limitation by grouping bridges, however other limitations were introduced.

\subsection{Petri-Net Based Models}

PNs (Petri 1962) are not as common as other stochastic techniques, but have been gaining momentum in infrastructure modelling, manufacturing and eco- nomics (British Standards Institution 2012). PNs have been used extensively in this study and are described in more detail in Section 3. Recent work by (Andrews 2013) suggests that PNs are suitable for infrastructure modelling as they have an inherent flexibility whilst maintaining the stochastic nature desired in bridge asset management modelling. The approach used 4 condition states to model deterioration ranging from a new condition to a condition requiring line speed restrictions. The model was designed for track asset management, however many of the techniques shown are transferable.

Another study performed by Rama \& Andrews 2013 split the model into smaller modules known as "Sub-Nets" which usually perform a specific function e.g. an inspection Sub-Net. A number of different Sub-Nets were developed to model component deterioration, inspection and intervention. A modelling hierarchy was presented in which the Sub-Nets were linked to interact with one another. An interesting addition was the inclusion of a resource allocation SubNet. This was created to simulate if a maintenance team was occupied or not. The authors mention that having a library of different Sub-Nets would make it easier to create a modular modelling system where the relevant Sub-Nets were linked together to create a detailed model of the real-world system.

Bridge asset management models have been created using PNs (Le \& Andrews 2014a, Le \& Andrews 2014b). The study focused on metallic bridges. A number of Sub-Nets were created to model the different processes. Again, 4 condition states were selected, however rather than describe the condition of the element, they were aligned with the intervention that would be required to repair the element i.e. rather than being in a "good" state, the state was marked "requires minor intervention". This system makes the condition more clear from a management perspective (Yang, Pam, \& Kumaraswamy 2009). The model includes both the condition of the metallic element and the element coating, a vital factor in the corrosion of metallic elements. The authors run simulations on the model; the simulated period was 60 years which took 10 minutes to simulate with convergence reached after 200 simulations.

The models which have been described show the application of PNs in infrastructure asset management modelling. They provide a convincing argument that PNs are suitable for this type of modelling and that they are useful for bridge asset management modelling. Considering the flexibility required in the model and the numerous Markov limitations (see Section 2.1) it may be preferable to use PNs for bridge asset management modelling.

\section{PETRI-NETS}

A PN is a directed bipartite graph. There are two types of nodes: places, which represent system states 
and transitions, which connect the places. Tokens occupy places and are representative of bridge elements in this study. I.e. an element, represented by a token, could occupy the place marked "poor condition" which would indicate the condition of the element. Transitions move the token from place to place, indicating a movement in the element condition; this could be used to represent deterioration, for instance. Arcs are used to graphically show the dependencies between places and transitions. No two places or transitions can be joined directly with an arc. The components of a PN can be seen in Figure 1. More details about PNs can be found in Reisig 2013 .

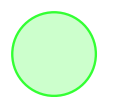

Place

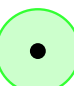

Place with token

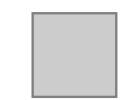

Transition
Figure 1: Components of a Petri-Net

\subsection{Coloured Petri-Nets}

Coloured Petri-Nets (CPNs), developed by Jensen 1997 are an extension to PNs. They allow a number of sophisticated features to be built into PNs. Firstly, each of tokens holds the ability to contain data within them, known as tuple information. This is useful for identifying individual elements and tracking them through the model. The fact that tokens are now distinguishable means that transitions act differently upon them. This has the benefit of the models being more compact as when more elements are to be modelled it is simply a case of adding in the appropriate number of tokens (British Standards Institution 2004). The second feature that CPNs enable is advanced transition functions. Rather than the basic rules which apply to transitions in PNs, CPNs allow customised transitions. This allows PNs to be married to programming code to make advanced transitions that perform sophisticated decisions. In the case of bridge management, this allows some of the processes to be mimicked more closely and more elegantly than with simple PNs.

\section{DETERIORATION, INSPECTION AND MAINTENANCE POLICIES}

\subsection{Condition States}

Network Rail (NR) identify different defects for different material types. Each of the defects has a gradated scale according to their extent. This system is known as the Severity Extent Rating (SevEx). The SevEx state is used to identify the defect and the extent of the defect, but varies according to material type. Materials that suffer from a wider array of defects have more SevEx states overall. For example, with concrete structures, the exemplar material type selected for this study, the 31 SevEx ratings range from A1, the new condition, to G6, permanent structural deformation. When looking at historical data, it is clear that the most common defects for concrete are cracking and spalling. Nielsen, Raman, \& Chattopadhyay 2013 found that cracking and spalling is the major driver in $89.9 \%$ of all concrete defects. The defect definitions and extents for concrete structures can be seen in Table 1 .

Table 1: SevEx defect definitions and extents for concrete structures (Network Rail 2012)

\begin{tabular}{|c|c|}
\hline Severity & Defect Definition \\
\hline A & No visible defects \\
\hline B & $\begin{array}{l}\text { Surface damage, Minor spalling, Wet- } \\
\text { ness, Staining, Cracking }<1 \mathrm{~mm} \text { wide }\end{array}$ \\
\hline $\mathrm{C}$ & $\begin{array}{l}\text { Spalling without evidence of corrosion, } \\
\text { Cracking } \geq 1 \mathrm{~mm} \text { wide without evidence } \\
\text { of corrosion }\end{array}$ \\
\hline $\mathrm{D}$ & $\begin{array}{l}\text { Spalling with evidence of corrosion, } \\
\text { Cracking } \geq 1 \mathrm{~mm} \text { wide with evidence of } \\
\text { corrosion }\end{array}$ \\
\hline $\mathrm{E}$ & Secondary reinforcement exposed \\
\hline $\mathrm{F}$ & Primary reinforcement exposed \\
\hline G & $\begin{array}{l}\text { Structural damage to element including } \\
\text { permanent distortion }\end{array}$ \\
\hline Extent & Definition \\
\hline 1 & No visible defects \\
\hline 2 & $\begin{array}{l}\text { Localised defect due to local circum- } \\
\text { stances. }\end{array}$ \\
\hline 3 & $\begin{array}{l}\text { Affects }<5 \% \text { of the surface of the ele- } \\
\text { ment. }\end{array}$ \\
\hline 4 & $\begin{array}{l}\text { Affects } 5 \%-10 \% \text { of the surface of the el- } \\
\text { ement. }\end{array}$ \\
\hline 5 & $\begin{array}{l}\text { Affects } 10 \%-50 \% \text { of the surface of the el- } \\
\text { ement. }\end{array}$ \\
\hline 6 & $\begin{array}{l}\text { Affects }>50 \% \text { of the surface of the ele- } \\
\text { ment. }\end{array}$ \\
\hline
\end{tabular}

\subsection{Inspection Interval}

NR policies describe two types of inspection. During a detailed inspection, each element of the structure is sketched and annotated with the defects. Then the appropriate SevEx condition is applied to each element and recorded. In accordance with the NR policies, detailed inspections are completed within touching distance. Visual inspections are carried out on an annual basis and are much less rigorous. They involve using the previous detailed inspection results and scanning the elements for any signs of significant condition change. No scoring is carried out during visual inspections. They are used to avoid risk of sudden failure as oppose to tracking long term corrosion. References to inspections in this work are referring to the detailed inspections.

The inspection interval guidelines are found in Network Rail 2010b. The SevEx condition is converted to 
a risk score from which the appropriate inspection interval can be found. Rather than have to convert from SevEx to the risk score to find the time interval, a back conversion was performed to be able to translate the SevEx condition directly to the inspection interval. This allows the inspection intervals to be built straight into the model allowing for dynamic selection during simulation.

Broadly, the policy suggests that elements which are in better condition require less monitoring. Those which are in poorer condition require closer monitoring. The policies state different inspection intervals for different materials. For concrete elements, the intervals are 12 years for elements in good condition, 6 years for elements in moderate condition and 3 years for elements in poor condition.

\subsection{Maintenance Actions}

NR perform inspections on the elements of their assets and produce a SevEx score for each of them. The SevEx score is then converted to an index known as the Bridge Condition Marking Index (BCMI). The BCMI is then used to check the appropriate maintenance action. Each material type is assigned a "Basic Safety Limit" which is a BCMI score that cannot be breached. Beyond the "Basic Safety Limit" the element would have to be replaced urgently. Overall there are three types of maintenance action: Minor Repair, Major Repair and Replacement. The threshold for Minor Repair starts where A1, the "as new" condition ends. The threshold for Major Repair is dependant on the material type. The Replacement threshold is set at the "Basic Safety Limit" of the particular material type. The limits are quite strict which often means that any defects are quickly dealt with and not left to develop further. The thresholds were back converted from BCMI to SevEx so that they could be directly incorporated into the model. This means that decisions on maintenance actions can be dynamically simulated in the model. The SevEx element conditions and their related maintenance actions can be seen in Table 2.

Table 2: Table showing the SevEx state thresholds for different maintenance actions.

\begin{tabular}{|l|l|}
\hline $\begin{array}{l}\text { Maintenance } \\
\text { Action }\end{array}$ & States \\
\hline $\begin{array}{l}\text { Minor Repair } \\
\text { Major Repair }\end{array}$ & B2-B4, C2-C3, D2 \\
Replacement & D6, E5-E6, F4-F6, G2-G6 \\
\hline
\end{tabular}

\section{DATA SOURCE}

A number of datasets were used for this study. The Structure Condition Marking Index (SCMI) database contains the records of element condition in both SevEx and BCMI; this can be used to track deterioration over time. The Cost Analysis Framework
(CAF) and MONITOR databases contain data regarding interventions; CAF is used for larger work items where exterior contractors were used. MONITOR is for smaller work items that the NR maintenance teams carry out. Finally, the Civil Asset Register and Reporting System (CARRS) contains the structure identification information used to marry up the information between the datasets.

The total number of bridges on which inspections were carried out is 25,949. Each bridge is split up into a hierarchy of: Major elements, Minor elements and Sub-Minor Elements. The total number of inspected Major elements is 273,427 . Each of those is split up into Minor elements. The total number of inspected Minor elements is 563,150 . Finally, the total number of inspections on Sub-Minor elements was 1,397,748.

This study uses concrete main girders as the exemplar element. This is because concrete bridges are becoming increasingly more popular and therefore their management will be progressively more important. Additionally, main girders are the main structural support of the deck and therefore one of the most critical elements. The total number of concrete bridges in the databases is 4,434. At least two inspections on the elements are required to ascertain the rate of change of condition. The number of repeat $(x \geq 2)$ inspections on concrete main girders totals 407,708 .

\section{PETRI-NET MODEL}

The modelling approach taken in this study is a bottom-up approach. To that effect, the model is on an asset and sub-asset level rather than a network level. The model itself represents a bridge asset with the tokens in the model representing the elements of the bridge. To model a complete asset, the appropriate number of tokens needs to added corresponding to the number of elements wished to be modelled. Interactions are carried out between the parent/child elements i.e. the condition of a Minor element depends on the condition of the Sub-Minor elements that it is comprised of. Interactions between parent/parent or child/child elements are not considered in this study, however the capability is present in the model. The model is organised into modules. Each of the modules mimics a different process; different techniques and data fitting procedures are used. The main modules that build the framework of the PN bridge model are the deterioration, inspection and intervention modules. An overview of their interactions can be seen in Figure 2.

\subsection{Deterioration}

\subsubsection{Calibrating Deterioration}

Element deterioration has been calibrated from historical data. When analysing the element inspections, those which are considered to show the effects of deterioration were processed into Mean Time to Fail- 
The deterioration module mimics the deterioration processes and rates found in historical data.
The inspection module, calibrated in accordance with NR policies for the inspection interval.
The intervention module is triggered after an inspection, it carries out the intervention and the element condition improves.

Figure 2: The overall framework of the PN model. The modules for deterioration, inspection and intervention are shown and how they interact.

ures (MTTFs). Failure in this instance refers to the movement from the initial condition to the destination condition. The MTTF was calculated with the following equation:

$$
\operatorname{MTTF}_{B 2 \rightarrow B 3}=\frac{t \cdot n_{B 2}}{m_{B 2 \rightarrow B 3}}
$$

where $m_{B 2 \rightarrow B 3}$ is the occurrences of elements that move from condition $B 2$ to condition $B 3 ; n_{B 2}$ is the number of elements that occupy condition $B 2$ at the beginning of the time interval and $t$ is the time interval. The failure rate can be calculated as follows:

$\lambda_{B 2 \rightarrow B 3}=\frac{1}{M T T F_{B 2 \rightarrow B 3}}$

where $\lambda_{B 2 \rightarrow B 3}$ is the failure rate between condition $B 2$ to condition $B 3$. In the PN model, each of the deterioration transitions are embedded with their corresponding failure rate. I.e. the transition which moves the token(s) from condition $B 2$ to condition $B 3$ will be embedded with $\lambda_{B 2 \rightarrow B 3}$ so that the same deterioration profile found from historical data can be replicated in the model. Each of these transitions is embedded with a different failure rate depending on the places they interact with. Table 3 shows some examples of the MTTFs and failure rates between condition states.

\subsubsection{Deterioration Module}

The deterioration module captures the profile of the element deterioration over time. The SevEx states, used by NR for condition monitoring, are used directly in the module to model deterioration. The advantages of using this system include: 1) allowing effective transformation from the SCMI database 2) exact defect definitions provided by the SevEx policy
Table 3: Example MTTFs calculated from historical data. Each transition in the deterioration module will be embedded with its corresponding failure rate depending on the places it connects.

\begin{tabular}{|l|rrr|}
\hline $\begin{array}{l}\text { State } \\
\text { From, } \\
\text { To }\end{array}$ & $\begin{array}{l}\text { Number } \\
\text { of Occur- } \\
\text { rences }\end{array}$ & MTTF (years) & $\begin{array}{l}\text { Failure rate } \\
\text { (years, } 10^{-2} \text { ) }\end{array}$ \\
\hline A1,B2 & 2335 & 292.2835 & 0.3421 \\
\hline A1,B3 & 23550 & 28.9801 & 3.4506 \\
\hline A1,C2 & 317 & 2152.9400 & 0.0464 \\
\hline B2,B3 & 1103 & 50.6817 & 1.9731 \\
\hline B2,C2 & 62 & 901.6451 & 0.1109 \\
\hline B2,C3 & 706 & 79.1813 & 1.2629 \\
\hline B3,B4 & 5046 & 62.0154 & 1.6125 \\
\hline B3,C3 & 3627 & 86.2779 & 1.1590 \\
\hline B3,C4 & 1437 & 217.7661 & 0.4592 \\
\hline
\end{tabular}

documents 3) avoiding conversion which has inherent losses associated with it and finally 4) the results of the simulation can be directly compared to the system already used by NR.

The module can be seen in Figure 3. The places, represented by the round nodes, are marked with the SevEx state that they represent. The transitions, represented by the grey squares, connect the places. For instance, transition $T 1$ connects places $A 1$ and $B 2$. This transition would be embedded with the failure rate corresponding to the historical movement of elements from $A 1$ to $B 2$. As elements deteriorate over time, this is mimicked in the model by tokens, representing elements, moving from place to place governed by the failure rates embedded in the transitions. This can be seen in the figure in places $B 2$ and $B 3$ as these are marked with tokens. This represents two Sub-Minor elements which are at different stages of deterioration. One of the advantages of CPNs is that tokens can be added to the module to represent as many elements as required.

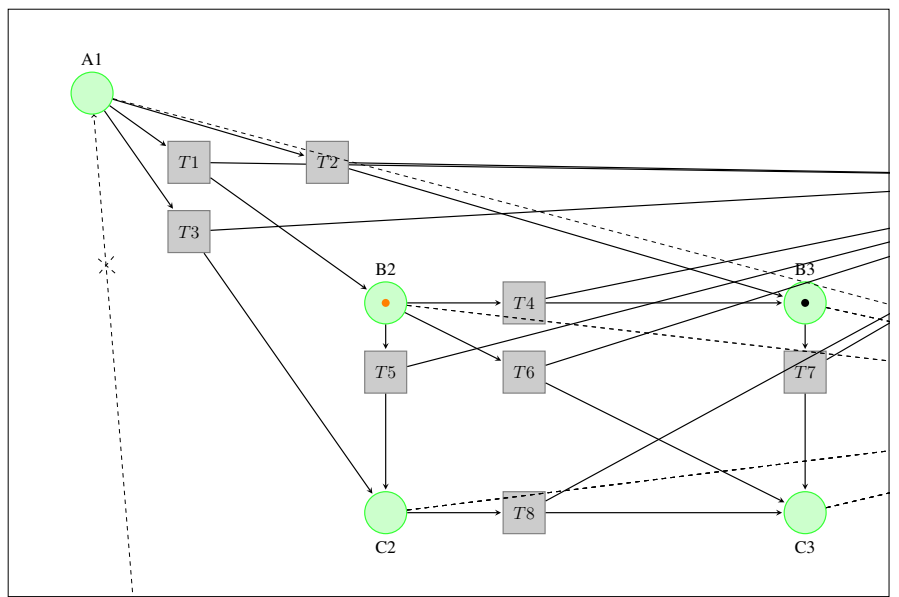

Figure 3: The PN deterioration module. States A1 to C3 are shown for clarity. For concrete elements the states, A1 to G6, total 31 states.

\subsection{Inspection Module}

The inspection module is designed to replicate the inspection process in accordance with NR policies (Net- 
work Rail 2010c). The condition of the elements, processed in the deterioration module, is a factor which the inspection module assesses. The NR policies have different inspection intervals depending on the condition of the element. The same guidelines are built into the inspection module, which can be seen in Figure 4.

The inspection module starts with transition $T 11$, which has dashed input arcs. These represent the decision making capability of the transition. It assesses the places to determine what condition the element is in from which the appropriate inspection interval can be selected. Once that time has passed, the transition absorbs the token from the "Between Inspection" state and outputs a token in the "During Inspection" state to show that the inspection process has begun. Once the inspection has been completed, transition $T 12$ reverts the module state back to "Between Inspection" where the module waits for the next inspection.

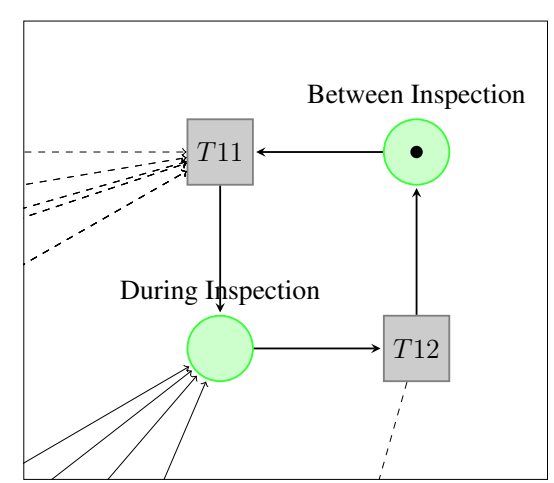

Figure 4: The inspection module analyses the condition of the elements from which decisions are made about the appropriate inspection interval Network Rail 2010a.

\subsection{Intervention Module}

The intervention module captures a number of complex processes in bridge management. It is the most complex module and takes input from a number of other modules. Once an inspection takes place, the appropriate maintenance action is decided upon. The first thing that the intervention module does (as seen in Figure 57) is to implement the according scheduling delay. This delay is designed to replicate the time it takes for the maintenance teams to request the possession of the asset and order the required materials. Different delay times are scheduled according to which intervention is selected. The more minor the intervention, the quicker it can be carried out and the fewer the materials required. This is carried out by transition $T 17$.

Once the maintenance teams get out to the element, there are two possibilities. The first is that the element is in the condition they were expecting and the work can be carried out as planned. In this instance, the intervention is completed and the condition of the element improved. The other possibility is that in the time it has taken to get the maintenance teams deployed, the element has deteriorated further. With el- ement deterioration, often the worse the condition the longer the intervention takes and the more resources required. In this instance, the maintenance teams will not have the required length of time or the resources to carry out the intervention. The intervention cannot be left half complete due to safety risks. Therefore the maintenance teams cannot continue; they must reschedule the intervention and return at a later date. This possibility was built into the model in accordance with industry experts.

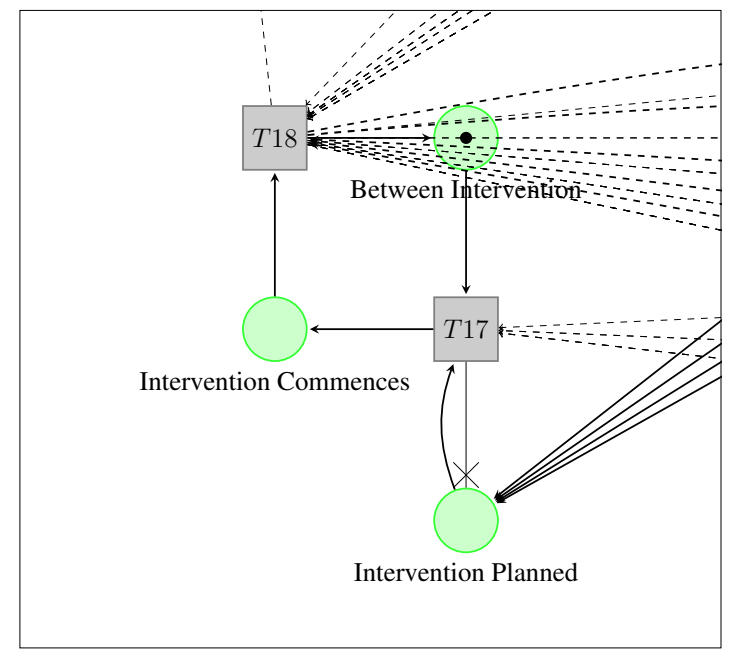

Figure 5: The intervention module is one of the most complex. It can be seen that the transitions have many dashed input arcs corresponding to all the advanced features that are built into this module.

\section{MODEL OUTPUTS}

Simulations can be run on the model to demonstrate how the modules interact, mimicking the effects of deterioration, inspection and intervention. Each of the elements of the bridge are introduced as tokens with their own deterioration profile. For illustrative purposes, an example simulation has been run with a single concrete main girder. If multiple elements were simulated the model outputs would be more difficult to understand due to the overlapping deterioration profiles. The simulation was carried out with the standard NR policies for inspection and maintenance. The simulation was carried out for 100 years, the design life for bridges (Eurocode 2001), and the element is initiated in the new (A1) condition.

The first model output, Figure 6, shows the probability of the element being in different condition states over time. The conditions relate to the SevEx conditions previously discussed. The element starts in a good condition and deteriorates in correlation with the historical data. Elements that are in good condition are only inspected ever 12 years in accordance with the NR policies. Hence, at the 12 year mark, the element is inspected and the condition revealed. From there the appropriate maintenance action, if required, is undertaken which improves the element condition. 
This process sets up the sawtooth pattern that propagates through the rest of the simulation. The NR policies are rigorous which means that defects are quickly resolved. Had the element been allowed to deviate into a poorer condition state, the inspection interval would have changed to a 6 or even 3 year cycle. This enables bridge portfolio managers to see the condition that the element(s) will be in with the current maintenance and inspection strategies.

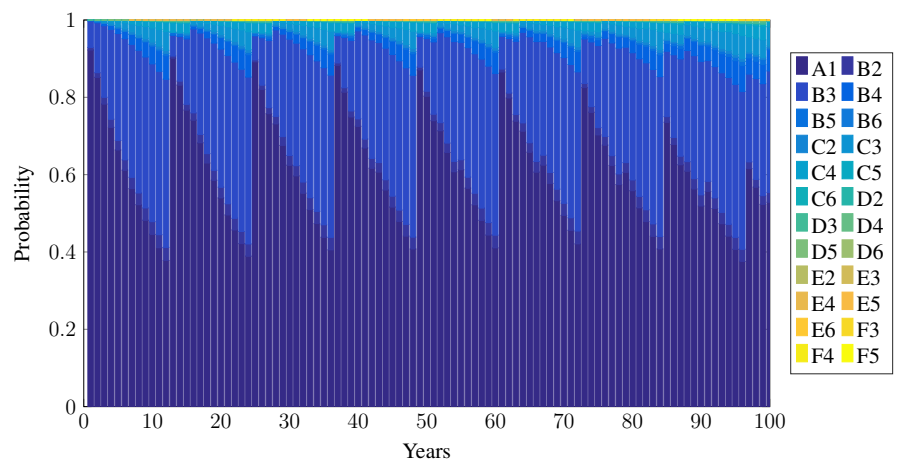

Figure 6: Graph to show the probability of being in different states over time.

A vital tool for bridge portfolio managers is to know when intervention will be necessary and what type of intervention it will be. To that effect, another one of the model outputs, shown in Figure 7 gives that information. In accordance with NR policies, the condition of the element is related to the type of work that will be required. Therefore it is possible to simulate the model and predict what type of intervention would be required if one was necessary. I.e. in year 10 , if an intervention was required, the most likely probability would be that it was a Minor Intervention. The results shown in Figure 7 contain the sawtooth pattern. Throughout the simulation the vast majority of the time only Minor interventions would be required. Just before the inspections, when deterioration is at its worst, there is an increasingly likelihood of requiring a Major intervention. Finally, the probability of requiring Replacement is minimal and is therefore difficult to see on the output graph. This facility can be used on case-study bridges to predict what type of interventions would be necessary at different points in the lifetime of the element; a vital tool for bridge portfolio managers.

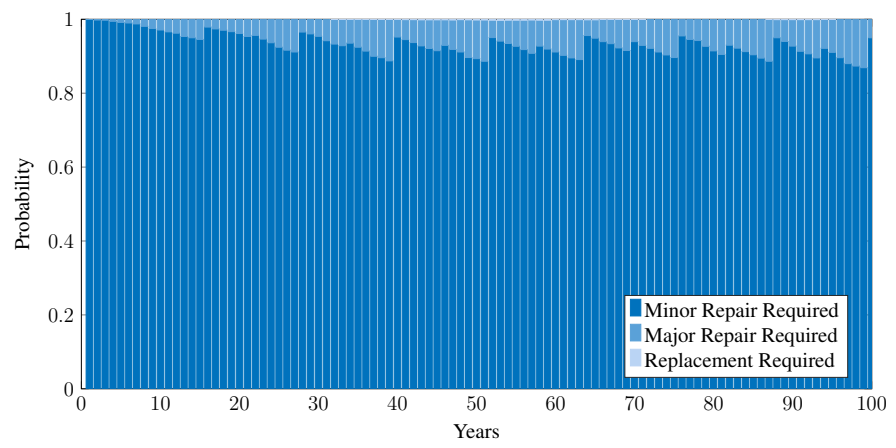

Figure 7: Graph to show the probabilities of different types of intervention over time.
Predicting upcoming costs is a critical facility when managing a portfolio of structures. Therefore historical data was analysed to ascertain the average cost of different types of intervention as well as the cost of inspection. Results of the simulation can be seen in Figure 8. The cost of inspections is relatively low, however inspections often give rise to maintenance actions, which are much more expensive. In this simulation, the standard NR policies were used which detects and rectifies defects quickly. Therefore the vast majority of the interventions were minor interventions. However, on the occasion that replacements had to be undertaken, their disproportionate costs drive up the cumulative cost. The costs are fairly regular across the simulation period, often coinciding with the inspection cycle as this is when defects would be detected. Bridge portfolio managers often need to be able to predict costs so that budgets can be approved; therefore this is an important tool in their arsenal.

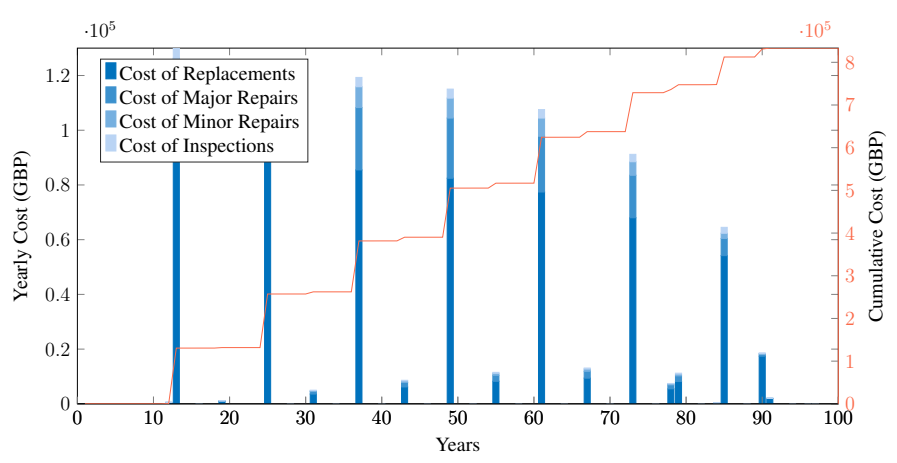

Figure 8: Graph to show the nominal and cumulative cost per year of interventions and inspections.

\section{CONCLUSION}

Model flexibility is critical to creating an effective modelling tool for bridge asset management. Bridges are varied across their population so a modelling approach that is able to accept different types of elements in whatever quantity required is a useful property. This gives the model the ability to move effortlessly from a small single span bridge to a large multispan bridge just with the allocation or reduction of tokens in the model. Additionally, being able to use historical data for the deterioration module and tying those into the current NR policies makes the model more robust.

One key difference of this model over others is the use of a 2-D condition state system. Most models use a linear system of conditions states (e.g. as new, good, poor). However this approach recognises that there are multiple failure modes and therefore a system which is able to replicate both the failure mode and the extent of the failure enhances the understanding of defect evolution.

The model is able to simulate whole bridges through the processes of deterioration, inspection and 
intervention. The example simulation shown previously gives model outputs that can give a good reflection of the condition of the element(s) over time as well as predicted maintenance and inspection costs. Considering that the model is calibrated with historical data and incorporates the current NR polices, the confidence in the outputs is boosted for bridge portfolio managers.

\section{ACKNOWLEDGEMENTS}

John Andrews is the Royal Academy of Engineering and Network Rail Professor of Infrastructure Asset Management. He is also Director of The Lloyds Register Foundation (LRF) Centre for Risk and Reliability Engineering at the University of Nottingham. Dovile Rama is the Network Rail Research Fellow in Asset management. Luis Canhoto Neves is a lecturer at the Nottingham Transport Engineering Centre (NTEC) at the University of Nottingham. Panayioti Yianni is conducting a research project supported by Network Rail and the Engineering and Physical Sciences Research Council (EPSRC) grant reference EP/L50502X/1. They gratefully acknowledge the support of these organizations.

\section{REFERENCES}

Andrews, J. (2013). A modelling approach to railway track asset management. Proceedings of the Institution of Mechanical Engineers, Part F: Journal of Rail and Rapid Transit 227(1), 56-73.

British Standards Institution (2004). Systems and software engineering. High-level Petri nets. Concepts, definitions and graphical notation. Technical report, British Standards Institution.

British Standards Institution (2012). Analysis techniques for dependability - Petri net techniques. Technical report.

Elbehairy, H., E. Elbeltagi, T. Hegazy, \& K. Soudki (2006). Comparison of two evolutionary algorithms for optimization of bridge deck repairs. Computer-aided Civil and Infrastructure Engineering 21(8), 561-572.

Eurocode (1996). Eurocode 2: Design of concrete structures Part 2: Bridges. Technical report.

Eurocode (2001). Eurocode 2: Design of concrete structures Part 2: Concrete Bridges. Technical report.

Frangopol, D. M., M.-J. Kallen, \& J. M. van Noortwijk (2004). Probabilistic models for life-cycle performance of deteriorating structures: review and future directions. Progress in Structural Engineering and Materials 6(4), 197-212.

Jensen, K. (1997). A brief introduction to coloured Petri Nets. In E. Brinksma (Ed.), Tools and Algorithms for the Construction and Analysis of Systems, Number 1217 in Lecture Notes in Computer Science, pp. 203-208. Springer Berlin Heidelberg.

Jiang, Y. \& K. C. Sinha (1989). Bridge service life prediction model using the Markov chain. Transportation Research Record (1223), 24-30.

Jiang, Y. \& K. C. Sinha (1989). Dynamic optimization model for bridge management systems. Transportation Research Record (1211).

Le, B. \& J. Andrews (2014a). Modelling Railway Bridge Asset Management using Petri-Net Modelling Techniques. In Proceedings of the Second International Conference on Railway Technology: Research, Development and Maintenance.
Le, B. \& J. Andrews (2014b). Petri net modelling of bridge asset management using maintenance related state conditions. Structure and Infrastructure Engineering, 2014..

Morcous, G. (2006). Performance prediction of bridge deck systems using Markov chains. Journal of Performance of Constructed Facilities 20(2), 146-155.

Morcous, G., Z. Lounis, \& Y. Cho (2010). An integrated system for bridge management using probabilistic and mechanistic deterioration models: Application to bridge decks. KSCE Journal of Civil Engineering 14(4), 527-537.

Morcous, G., H. Rivard, \& A. Hanna (2002). Modeling bridge deterioration using case-based reasoning. Journal of Infrastructure Systems 8(3), 86-95.

Network Rail (2010a). Handbook for the examination of Structures Part 11A: Reporting and recording examinations of Structures in CARRS. NR/L1/CIV/006/11A.

Network Rail (2010b). Handbook for the examination of Structures Part 1C: Risk categories and examination intervals. NR/L3/CIV/006/1C.

Network Rail (2010c). Handbook for the examination of Structures Part 2A: Bridges. NR/L3/CIV/006/2A.

Network Rail (2012). Structures Asset Management Policy and Strategy. pp. 219.

Nielsen, D., D. Raman, \& G. Chattopadhyay (2013). Life cycle management for railway bridge assets. Proceedings of the Institution of Mechanical Engineers, Part F: Journal of Rail and Rapid Transit 227(5), 570-581.

Petri, C. A. (1962). Kommunikation mit Automaten. Ph. D. thesis.

Rama, D. \& J. Andrews (2013). A System-wide Modelling Approach to Railway Infrastructure Asset Management. In Proceedings of the 20th Advances in Risk and Reliability Technology Symposium.

Reisig, W. (2013). Understanding Petri Nets: Modeling Techniques, Analysis Methods, Case Studies.

Robelin, C.-A. \& S. M. Madanat (2007). History-dependent bridge deck maintenance and replacement optimization with Markov decision processes. Journal of Infrastructure Systems 13(3), 195-201.

Scherer, W. \& D. Glagola (1994). Markovian Models for Bridge Maintenance Management. Journal of Transportation Engineering 120(1), 37-51.

Sobanjo, J. O. \& P. D. Thompson (2011). Enhancement of the FDOT's Project Level and Network Level Bridge Management Analysis Tools.

Yang, I.-T., Y.-M. Hsieh, \& L.-O. Kung (2012). Parallel computing platform for multiobjective simulation optimization of bridge maintenance planning. Journal of Construction Engineering and Management 138(2), 215-226.

Yang, Y. N., H. J. Pam, \& M. M. Kumaraswamy (2009). Framework development of performance prediction models for concrete bridges. Journal of Transportation Engineering 135(8), 545-554. 